\title{
ENSINO RELIGIOSO E ICONOGRAFIA
}

Religious education and iconography

\section{SILVEIRA, Valeska Freman Bezerra Freitas ${ }^{1}$ PUCSP - São Paulo/Brasil}

\begin{abstract}
RESUMO: Este artigo procura apresentar algumas reflexões a respeito da importância da transposição didática da Ciência da Religião para o Ensino Religioso no que se refere especificamente à análise iconográfica. Partindo dos pressupostos teóricos e metodológicos da Ciência da Religião, propomos uma análise cuidadosa da iconografia nos cursos de Ensino Religioso. Nosso objetivo é apresentar aos professores dessa disciplina esta aproximação teórico metodológica com a Ciência da Religião como possibilidade de desenvolver uma prática educativa que viabilize o aluno a compreender a imagem (texto) não como mera ilustração, mas como fonte histórica de grande relevância para a compreensão do estudo das religiões.
\end{abstract}

Palavras-chave: Ciência da Religião ; Ensino Religioso ; Iconografia.

ABSTRACT: This article seeks to present some reflections on the importance of the didactic transposition of the Science of Religion to Religious Teaching in what specifically refers to the iconographic analysis. Starting from the theoretical and methodological assumptions of the Science of Religion, we propose a careful analysis of the iconography in the Religious Education courses. Our objective is to present to the professors of this discipline this theoretical methodological approach with the Science of Religion as a real possibility to develop an educational practice that allows the student to understand the image (text) not as a mere illustration, but as a historical source of great relevance for the Understanding of the study of religions.

Keywords: Science of Religion ; Religious Education ; Iconography.

1 Doutoranda em Ciências da Religião; Mestre em Ciências da Religião pela Pontifícia Universidade Católica de São Paulo (PUCSP), Licenciada e Bacharel em História (PUCSP) E-mail: valeska28freman@gmail.com

REVISTA RELEGENS THRÉSKEIA - 2018 - UFPR - UEPA 


\section{Introdução}

O objetivo deste artigo é apresentar aos professores de Ensino Religioso algumas reflexões a respeito da importância da transposição didática da Ciência da Religião para o Ensino Religioso no que se refere especificamente à análise iconográfica.

Acreditamos que esta aproximação teórico metodológica com a Ciência da Religião colaborará para que os professores desta disciplina possam aprimorar sua prática educativa no sentido de desenvolver, junto aos alunos, uma leitura mais problematizadora a fim de compreende-las não como simples ilustração, mas como fonte histórica de fundamental importância para o estudo das religiões.

Importância da análise iconográfica na sala de aula

A linguagem humana é feita de palavras que se traduzem em imagens e de imagens que se traduzem em palavras

( MANGUEL, Alberto², 2003 )

De acordo com Cláudio Pastro ${ }^{3}$ e o André Tavares ${ }^{4}$, a palavra 'iconografia', de origem grega, significa "comunicar-se, escrever, através de imagens." ( PASTRO e TAVARES, 2010, p.39) e como imagem compreendemos os meio de expressão e representação feita pelos seres humanos nos diferentes tempos e espaço.

É mister reconhecermos, enquanto educadores, a importância das imagens no processo de leitura e compreensão do mundo. Difundidas pela internet, TV, cinema, outdoors, jornais, revistas, fotografias, tablets, ifones, elas estão muito presentes em nossa vida. Embora sejamos inundados por imagens em todo o tempo e lugar, na

\footnotetext{
2 Cf. MANGUEL,Alberto Nasceu em Buenos Aires, em 1948, e passou a infância em Israel. Morou na Espanha, na Itália,na França e na Inglaterra e no Taiti. Em 1985 naturalizou-se como cidadão canadense. Manguel trabalha informações enciclopédicas com rigor e elegância. Sua leitura abrange desde obras da Roma antiga até as arrojadas experiências da arte do século XX, passando por Caravaggio e pelo brasileiro Aleijadinho.

3 Cf. PASTRO, Cláudio Desde 1975, o artista paulistano, Cláudio Pastro se dedica à arte Sacra. Suas pinturas são encontradas em muitas Igrejas e capelas do Brasil, inclusive na Basílica de Aparecida, e em várias partes do mundo. Foi o artista escolhido pela Santa Sé para conceber a imagem do Cristo Evangelizador do Terceiro Milênio, obra permanentemente exposta no Vaticano. É considerado o Michelangelo brasileiro.

4 Cf. TAVARES, André. Frade dominicano. Redator da Revista Dominicana de Teologia. Bacharel em Teologia pela Escola Dominicana de Teologia, de São Paulo, afiliada ao Angelicum
}

REVISTA RELEGENS THRÉSKEIA - 2018 - UFPR - UEPA 
maioria das vezes até as vemos, mas poucas vezes as lemos. Ou seja, identificamos a sua presença, mas nem sempre somos capazes de fazer uma leitura mais minuciosa de seu conteúdo de modo a estabelecer a relação entre passado (quando foi produzida) e presente (quando a estamos vendo). Quando agimos desta maneira, corremos o risco de passarmos por elas sem deixar que colaborem para a nossa reelaboração de visão de mundo.

A proposta desse artigo é justamente levantar a possibilidade de trabalharmos a iconografia no Ensino Religioso a partir de uma abordagem metodológica da Ciência da Religião ,por acreditar que esta é capaz de proporcionar a leitura das imagens de maneira mais dialógica e crítica. É necessário que busquemos uma metodologia que possibilite as imagens falarem a que vieram, que possibilite-nos contemplá-las, inquirilas num diálogo silencioso, mas marcado pela curiosidade, pelo levantamento de hipóteses, pela vontade de se aproximar da verdade de quem as produziu; tudo com vistas a conhecermos um pouco mais do outro e de nós mesmos.

Nesse sentido o estudo das imagens precisa ser executado de maneira mais sistemática, e não interpretado como simples desenhos com função meramente ilustrativa, mas sim como possibilidades de aprofundar a análise dos processos históricos e seus personagens. Como reafirma Paiva:

\begin{abstract}
A iconografia é tomada agora como registro histórico realizado por meio de ícones, de imagens pintadas, desenhadas, impressas ou imaginadas (...). São registros com os quais os historiadores e os professores de História devem estabelecer um diálogo contínuo. É preciso saber indagá-los e deles escutar as respostas. (PAIVA, 2006, p. 17)
\end{abstract}

Dada a sua importância, cabe não somente os historiadores citados por Paiva, mas todos os educadores, inclusive os de Ensino Religioso promoverem atividades em que os alunos possam ler as imagens, possam estabelecer as conexões entre a cor, a forma, a sombra, a disposição dos objetos e das pessoas, e neste projeto especificamente, relacionarem as técnicas de produção com as concepções de fé e sagrado.

Imagens bíblicas, tribais, de lugares sagrados, de vitrais, de paredes, de arcos, da natureza, de seres humanos, de animais, de rituais, enfim, todas elas refletem os medos, 
desejos e visões de mundo de um povo, são guardiãs da memória. No estudo das religiões, a análise das imagens tem uma importância ímpar uma vez que, na maioria das vezes, como afirma Cláudio Pastro (1993), as imagens palpáveis acabam por construir nas pessoas a imagem do invisível, ou seja, buscam representar ideias como: o espírito, o(s) deus(es), a força sobrenatural, a energia, os anjos, o bem, o mal, o céu, o inferno, e tantos outros.

Em comunidades que não possuem a cultura escrita, como algumas tribos indígenas ou africanas, a leitura de imagens, consideradas por alguns autores como arte religiosa, torna-se ainda mais importante para a compreensão da cultura e tradição religiosa desses povos.

Mas o que define uma arte religiosa? De acordo com César Augusto Sartorelli, é a função que a arte desempenha na comunidade religiosa que definirá o seu caráter religioso ou não. Para Sartorelli, a arte religiosa é aquela que foi "utilizada" com 'o objetivo de servir a fins ritualísticos ou de expressão das várias faces das religiões e crenças"( SARTORELLI, In USARSKI, 2013, p.557). Ainda segundo o autor a arte religiosa pode ser sacra para determinadas tradições religiosas, ou somente religiosa para outras tradições "A cruz é um símbolo religioso para cristãos, mas não é por exemplo para islâmicos" (Ibidem, p.557).

Cláudio Pastro e André Tavares, por sua vez apresentam outros termos para definirem arte religiosa e arte sacra, definições essas que em muito colaboram para que possamos refletir sobre a proximidade entre essas expressões artísticas o Ensino Religioso e a Catequese. Vejamos essas diferenças nas palavras dos próprios artistas, que para explicarem arte sacra citam a definição do Catecismo da Igreja Católica :

A arte sacra é verdadeira e bela quando responde, por sua forma, à sua
vocação própria: evocar e glorificar, na fé e na adoração, o Mistério
transcendente de Deus, beleza excelsa e invisível de verdade e amor,
revelada em Cristo, "resplendor de sua glória, expressão de seu Ser (
Hb 1,3), em que "habita corporalmente toda a plenitude da divindade"
(Cl 2,9), beleza espiritual refletida na Santíssima Virgem Maria, Mãe
de Deus, nos anjos e santos. A arte sacra verdadeira leva o homem à
adoração, à oração e ao amor de Deus Criador e Salvador, Santo e
Santificador" 5 (Catecismo da igreja Católica, n.2.502, In. PASTRO e
TAVARES, 2010, p.45)

5 O Catecismo da Igreja Católica é um texto de referência sobre a fé católica e a doutrina da Igreja. Nele podemos conhecer os elementos fundamentais e essenciais da fé cristã. A veracidade e confiança dos escritos, dá-se pelo fato dele ser considerado, pelos eclesiásticos ,como "fiel e iluminado pela Sagrada Escritura, pela Tradição Apostólica e pelo Magistério da Igreja.

REVISTA RELEGENS THRÉSKEIA - 2018 - UFPR - UEPA 
A arte religiosa, por sua vez, ainda segundo Pastro e Tavares, nasce fundamentalmente a partir do final do século XIII, com o surgimento dos estilos góticos, seguidas pelos estilos renascentista, barroco, neoclássico,até o início do século XX . De acordo com Pastro esses estilos estão associados à arte religiosa, pelo fato de descartarem "a religião e verem mais a interpretação humana que a acolhida do Mistério" ( PASTRO e TAVARES, 2010, p. 46).

No primeiro milênio há uma predominância da arte sacra, o Cristianismo , marcado pela herança da Antiguidade mítica, é expresso a partir da fé. O gótico inaugura o segundo milênio, dando os primeiros passos para uma arte mais racional; graças à influência nórdica mais espiritualizada e menos sacra a qual racionalmente se estuda espaço, cores, luz. " Já não temos mais a leitura bíblica, isto é, o espírito falando a linguagem, na postura humana" (PASTRO e TAVARES, 2010, p. 47) .

Como podemos observar, o compromisso da arte religiosa parece se aproximar mais da arte, e menos do Mistério, é uma arte que diz mais da técnica do que do transcendente. As artes religiosas "do ponto de vista artístico e estético, buscavam a perfeição visual: a perspectiva, saber desenhar a profundidade de uma paisagem, saber desenhar com perfeição o corpo humano" ( PASTRO e TAVARES, 2010, p. 46)

Essas breves conceitualizações sobre arte sacra e arte religiosa nos apontam para aproximarmos mais a primeira aos propósitos da catequese, ou seja o de pensar a arte, no caso a imagem, enquanto objeto de conversão, de credo; enquanto a segunda, aos objetivos do Ensino Religioso, ao procurar estar mais comprometida com o aspecto técnico, artístico da obra, sem, no entanto, desprezar o seu conteúdo religioso, que se apresenta muito mais enquanto conhecimento, "conteúdo" propriamente dito, do que experiência de fé. Para Pastro e Tavares o "primeiro sentimento que deve animar o artista sacro é a fé", ( PASTRO e TAVARES, 2010, p. 46), assim como os catequistas, diferentemente do/a professor/a de Ensino Religioso que fundamentará sua relação com a imagem a partir de um método investigativo e não de fé.

No entanto, faz-se necessário considerar que no diálogo com as imagens temos pelo menos duas dimensões : a primeira que seria a metodológica, considerada uma das ferramentas que busca estabelecer uma relação mais sistematizada, problematizadora, "científica", e a segunda dimensão seria a que Manguel considera como a própria experiência do leitor. De acordo com Manguel, seja qual for a imagem, dos museus, dos 
livros de arte, e por que não, dos livros didáticos, ela sempre nos apontará escolas distintas, de épocas distintas e de países distintos ; porém nossa leitura passa por outros elementos, além dos técnicos como afirma ele:

\begin{abstract}
Vemos uma pintura como algo definido por seu contexto; podemos saber algo sobre o pintores sobre o seu mundo; podemos ter alguma ideia das influências que moldaram sua visão, (....) - mas, no fim, o que veremos não é nem a pintura em seu estado fixo, nem uma obra de arte aprisionada nas coordenadas estabelecidas pelo museu para nos guiar. $\mathrm{O}$ que vemos é a pintura traduzida nos termos da nossa própria experiência"(MANGUEL, 2003, p. 27)
\end{abstract}

Nesse sentido, ler imagens é um procedimento e, ao mesmo tempo, uma habilidade que cabe ao professores mediar, a partir de uma metodologia específica de análise, sem desconsiderar as experiências pessoais dos alunos. Trata-se de um aprimoramento do exercício do olhar, de busca da intencionalidade, do foco, das cores, da ausência ou presença de personagens, buscando ir além do explícito. Ler imagens é um diálogo com "representações" do real, carregadas de sentido e significado. No entanto, assim como as demais fontes históricas, a imagem não se esgota em si mesma precisa ser interrogada, avaliada e contraposta a outros suportes.

Transposição didática da Ciência da Religião para a leitura iconográfica no Ensino Religioso

Cientistas da religião que trabalham apenas com textos são como cegos que falam de paisagens que lhes foram descritas em palavras, por pessoas que podem ver (GRESCHAT, 2005, p. 77)

Nossa opção em propor uma transposição didática da Ciência da Religião para a leitura iconográfica no Ensino Religioso se fez, por acreditarmos que no plano acadêmico, ela venha conquistando cada vez mais o estatuto de disciplina autônoma e de referência para o estudo das religiões.

Valendo-se de uma epistemologia que não privilegia uma religião em detrimento 
das outras, a Ciência da Religião entende o religioso como objeto de conhecimento, pautada pelos princípios do respeito e da valorização da pluralidade religiosa. Nesse sentido consideramos que a metodologia da Ciência da Religião , pode ser aplicada em diferentes materiais pedagógicos, seja em coleções de Ensino Religioso, seja em materiais produzidos pelos próprios professores da disciplina .

Ou seja, entendendo o Ensino Religioso enquanto importante Área do Conhecimento $^{6}$, só nos caberia reconhecer a Ciência da Religião como a disciplina de referência para a sua aplicação, como justifica Afonso Maria Ligorio Soares :

A opção por um Ensino Religioso desvinculado da confessionalidade é precondição para que nos sirvamos da área da Ciência da Religião. No entanto, além de historicamente localizáveis, ainda fazem parte de nossa realidade escolar outros modelos de Ensino Religioso, com distintas bases teóricas e metodológicas que, por sua vez, geram conteúdos e posturas ( políticas e didáticas) nas situações de Ensino aprendizagem (SOARES, 2010, p.120)

À Ciência da Religião enquanto fundamento teórico, social e pedagógico para o Ensino Religioso garante, de acordo com Passos, uma autonomia a essa área do conhecimento, capaz de inviabilizar sua associação à modelos catequéticos e teológicos. A Ciência da Religião, segundo o autor é a única apta à sustentar uma autonomia epistemológica e pedagógica do Ensino Religioso de maneira a garantir não uma formação de pessoas religiosas ou o fortalecimento da fé, mas sim a formação cidadã, e agregar a ela saberes tão importantes como os saberes matemáticos, linguísticos, históricos, filosóficos, etc. Como afirma Passos:

A discussão do ER não se inscreve, fundamentalmente, na esfera do debate sobre o direito ou não à religiosidade, mas do direito à educação de qualidade que prepare o cidadão para visões e opções conscientes e críticas em seus tempos e espaços. (PASSOS, 2007, p.76-77)

\footnotetext{
${ }^{6} \mathrm{O}$ Art. $1^{\circ}$ do projeto de lei n. ${ }^{\circ} 1.065$-a, de 2007 - Câmara dos Deputados, considera "O ensino religioso, disciplina da área de conhecimento da educação religiosa e parte integrante da formação básica do cidadão (...)"
} 
Acreditamos ser necessário aos professores de Ensino Religioso, comprometidos com uma leitura mais crítica e analítica das imagens, assumirem uma postura teórico metodológica semelhante a dos cientistas da religião, pois de acordo com Soares , é o cientista da religião o mais indicado para essa transposição didática, pois ele até pode ter suas convicções religiosas e cumprir prazerosamente certas práticas rituais, mas sabe também, quando oportuno, olhar as religiões a partir de uma perspectiva profissional (SOARES,2010, p.20)

Ainda sobre o papel do cientista da religião, Greschat enfatiza a importância que esse profissional deve dar à leitura de imagens e não somente textos. Segundo o autor os textos sagrados "são mais importantes para sacerdotes do que para leigos, mas nem estes, nem aqueles contentam-se com eles" (GRESCHAT, 2005, p.63). Para Greschat, mesmo considerando a importância que cada religião atribui às imagens , é impossível conhecê-las somente através dos textos sagrados. Para o autor, somente quando os cientistas da religião passarem a considerar as fontes iconográficas em suas pesquisas é que deixarão de "se referir às religiões alheias de olhos fechados" (GRESCHAT, 2005,p. 77).

Greschat considera que as imagens são um rico e fundamental recurso a ser explorado pelos cientistas da religião, uma vez que, segundo ele, as palavras não dão conta de explicar o real, principalmente quando se trata de algo desconhecido do leitor /ouvinte . Nada mais certo, para Greschat do que o provérbio "Uma imagem vale mais do que mil palavras" (GRESCHAT, 2005,p. 64 ) já que para ele as imagens cumprem melhor essa função de aproximar o leitor da compreensão de seu objeto. Vejamos sua justificativa:

Uma cerimônia religiosa requer lugares apropriados, vestimentas próprias, utensílios específicos e ícones respectivos. É difícil descrever esses itens em textos. Nem todos os leitores são suficientemente hábeis para imaginar em conjunto dados técnicos a respeito de altura ou diâmetro, peso ou análises de fundo e camadas de cores. Quem se refere a algo que leitores e ouvintes conhecem é facilmente compreendido. A caracterização de objetos desconhecidos por meio de palavras exige muito mais do que apenas uma medíocre capacidade de observação e expressão. Como se deve descrever uma obra de arte para ouvintes que nunca tiveram a chance de vê-la? Como a praxe de qualquer curso da Ciências da Religião pode equivocadamente provar, 
um dispositivo projetado na parede por dos minutos livra o professor de longos discursos e evita mal-entendidos por parte dos alunos. (GRESCHAT, 2005, p. 64 )

A função pedagógica das imagens religiosas, apontada por Greschat, não traz novidade do ponto de vista da conversão, basta relembrarmos quanto a Igreja Católica investiu nesses recursos durante a Idade Média. Esculturas, pinturas, músicas, imagens de modo geral , foram utilizados pelo clero católico como elementos "pedagógicos" no sentido de transmitir à população, maioria analfabeta, os princípios e valores cristãos.

Não apenas o catolicismo se valeu das imagens para transmitir seus ensinamentos, mas também várias religiões a utilizaram e continuam utilizando. $\mathrm{O}$ próprio Greschat cita o exemplo dos budistas:

Desde muito tempo um episódio da biografia de Buda serve como modelo para conversão ao budismo. Trata-se de uma série de quatro cenas.(...) As imagens representavam as quatro vezes em que ele deixou sua casa em uma carruagem pomposa e nas quais conheceu o verdadeiro mundo. Tais saídas fizeram que os olhos do príncipe se abrissem para a realidade : pela primeira vez ele viu um idoso, um doente e um morto em três encontros que acabaram com sua ingenuidade graças ao insight : "Sofrerei o mesmo destino!". A quarta saída mostrou-lhe uma alternativa para escapar da calamidade: ele observou um monge itinerante, vestido com uma túnica vermelha. Quem retém essas cenas na memória e viaja pelo Sudoeste da Ásia pode reencontrá-las diariamente e até mesmo confirmar sua verdade universal, pelo menos no que diz respeito às trê primeiras.(GRESCHAT, 2005, p. 66 )

A partir desta narrativa budista e de outras tradições religiosas encontradas em seus escritos, Greschat enfatiza o lugar extremamente relevante que as imagens ocupam para o processo de conversão em algumas religiões, e nos aponta também a relação direta entre imagens e memória, "as imagens deixam uma marca duradoura na memória. Nelas se manifestam sutis experiências subjetivas. Ensinam como o invisível pode ser enxergado no visível"(GRESCHAT, 2005,p.67)

Logo , podemos observar a importância que o autor dá a análise das imagens dentro e fora da sala de aula, pois para ele " não existe nenhuma razão que faça com que cientistas da religião enxerguem apenas letras quando há tanto mais para ser visto".

( GRESCHAT, 2005, p.64)

REVISTA RELEGENS THRÉSKEIA - 2018 - UFPR - UEPA 
No entanto, há de se considerar que, quando os cientistas da religião se deparam com religiões em que as imagens são proibidas ,estas perdem essa força "pedagógica". Nesses casos, as escrituras passam a ter função primordial para a compreensão das tradições.

Greschat salienta que são os livros, principalmente para os educadores, os grandes suportes das imagens. Nesse sentido, ainda segundo o autor, cabe ao cientista da religião, estar atento em distinguir entre as publicações aquelas em que as imagens ocupam um lugar e uma função irrelevante no corpo do texto e as que a consideram enquanto fonte de conhecimento.

Essas observações de Greschat sobre o lugar e função das imagens nos livros deveriam pautar as atividades dos professores de Ensino Religioso, seja como um dos critérios para a escolha do livro didático, seja no desenvolvimento de atividades que proponham ,junto aos seus alunos, uma análise mais rigorosa das imagens.

Interessante lembrarmos a importância deste antigo recurso didático para o processo de educação no Brasil. O livro didático continua presente nas salas de aula desde o século XIX, tanto nas escolas públicas, quanto particulares e apesar da concorrência inovações tecnológicas, tais como mimeógrafos, slides, vídeos, dvds, internet, ele ainda permanece ocupando um lugar extremamente relevante no processo de ensino aprendizagem. Segundo Bittencourt, ele continua sendo utilizado "nas mais variadas salas de aula e condições pedagógicas, servindo como mediador entre a proposta oficial expressa nos programas curriculares e o conhecimento escolar ensinado pelo professor" .( BITTENCOURT 2008 , apud SILVEIRA 2016, p. 72)

Os livros didáticos de Ensino Religioso, marcadamente nas escolas particulares, não são exceção a essa função de mediador das relações de aprendizagem entre os professores e os alunos . Pelo contrário, essa condição se acentua e muito, principalmente nos anos iniciais da Educação Infantil e Ensino Fundamental I, em que são pouquíssimos os casos em que encontramos professores dessa disciplina com formação em Ciência da Religião ou nas disciplinas "auxiliares" como a História, a Filosofia, a Teologia, as Ciências Sociais e outras. Na maioria das escolas é a própria professora da série, cuja formação é Pedagogia, a profissional responsável por ministrar o curso de Ensino Religioso aos alunos. A ausência de formação acadêmica nessa área do conhecimento colabora para uma maior dependência desses educadores com relação 
ao livro didático, podendo tornar-se um verdadeiro "depositário de conteúdos escolares":

O curso fica estritamente dependente da condução e da visão do autor do livro didático, e/ou de uma visão particular subjetiva do docente. Há um empobrecimento da disciplina, um descompromisso com o processo de ensino/aprendizagem mais reflexivo, critico e objetivo. Nesse sentido, corre-se o risco de uma abordagem mecanicista e pouco reflexiva, devido à falta de repertorio, ou seja, uma deficiência na formação acadêmica. ( SILVEIRA, 2016, p.40)

Outro aspecto a se levar em conta, com relação à especificidade dos livros didáticos de Ensino Religioso, refere-se ao seu processo de elaboração e produção. Trata-se de um processo antigo e nos remonta aos nossos primeiros anos de colonização $^{7}$, no entanto o modelo que encontramos atualmente, ao contrário das demais disciplinas, não possui nenhuma indicação do MEC, ficando a critério dos autores e editoras os conteúdos, valores éticos, exercícios e toda sua concepção. O fato de não haver $\operatorname{PNLD}^{8}$ ( Plano Nacional do Livro Didático) para os livros de Ensino Religioso dificulta que estes passem se quer por uma exigente avaliação do MEC.

Logo, podemos concluir que, dada a importância que o livro didático ocupa nas relações de ensino /aprendizagem, nas escolas particulares confessionais, somadas à ausência de educadores especialistas na área de religião, realidade da maioria das escolas brasileiras, aliadas ao frágil direcionamento em termos de conteúdo e metodologia na produção dos livros didáticos de Ensino Religioso, a responsabilidade dos professores de Ensino Religioso aumenta consideravelmente. A esses profissionais cabe a análise extremamente crítica e minuciosa do livro didático, como afirma Bittencourt :

É importante observamos se os autores de Ensino Religioso estão contribuindo, em suas obras, para os leitores aprenderem a ler as

7 Sobre a história do livro de Ensino Religioso ler JUNQUEIRA, Sérgio Rogério e Azevedo KLUCK, Claudia Regina Condello Cândido de Oliveira. História do Livro Didático do Ensino Religioso brasileiro. In: X Congresso Brasileiro de História da Educação, v.10, p.1-10, 2014.

8 Programa Nacional do Livro Didático - PNLD. Disponível em: http://portal.mec.gov.br/pnld/apresentacao Acesso em 24/05/2017

REVISTA RELEGENS THRÉSKEIA - 2018 - UFPR - UEPA 
imagens ou se elas aparecem apenas para "tornar as páginas mais atrativas para os jovens leitores" (BITTENCOURT, 2008, p. 70).

\section{Leitura problematizadora das imagens e a Ciência da Religião}

Foco de preocupação deste artigo, também caberá aos professores de Ensino Religioso analisar junto aos alunos várias questões referentes às imagens tais como: a presença de legendas, a qualidade das informações que compõem a legenda, a pertinência do conteúdo, a que parte do texto as imagens fazem referência; assim como o tamanho da imagem, o espaço que ocupam na página, a qualidade da reprodução; enfim elementos aparentemente associados à questões editoriais, mas que dizem muito sobre a editora, os/as autores/as e suas relações com o tema, com a religião em foco. ${ }^{9}$

Outro aspecto a ser considerado neste processo de análise iconográfica refere-se à autoria e à maneira como as imagens foram produzidas, pois essas questões nos apontam para um dos principais objetivos desta metodologia de trabalho, que é pesquisar a origem da iconografia pesquisada (se produzida por pintores, fotógrafos, cientistas, fieis); assim com analisar as condições de produção do material iconográfico estudado.

Dessa maneira, caberá aos professores de Ensino Religioso propor instrumentos para que seus alunos possam analisar que tipo de imagens são apresentadas: bíblicas, tribais, de lugares sagrados, de vitrais, de paredes, de arcos, da natureza, de seres humanos, de animais, de rituais. E também essas imagens foram produzidas e quem as produziu, se os seus próprios fiéis ou pesquisadores.

Nesse processo de leitura problematizadora das imagens, as questões relativas à produção e reprodução delas devem fazer parte desse trabalho. É necessário que os alunos percebam que as imagens são produzidas e reproduzidas por pessoas de diferentes tradições religiosas, ou mesmo sem nenhuma pertença, bem como por distintos grupos econômicos e políticos e, por governantes em determinado tempo e espaço, e que tais autorias revelam perspectivas, intencionalidade dos produtores e

9 Citamos abaixo, uma dissertação de mestrado e uma publicação, em que ambas têm entre seus objetivos apresentar propostas metodológicas para a análise e estudo das imagens que compõem os livros didáticos de Ensino Religioso. Os dois trabalhos desenvolveram análise de coleções de livros didáticos de Ensino Religioso SILVEIRA, Valeska Freman B. F. . Entre a teoria e a prática: limites da aplicação da Ciência da Religião na produçao dos livros didáticos de Ensino religioso no Fundamental I (Dissertação em Ciência da Religião ), PUC-SP, São Paulo, 2016. DINIZ, Debora;LIONÇO, Tatiana;CARRIÃO, Vanessa.Laicidade e Ensino Religioso no Brasil. Editora letras livres / Editora unb / UNESCO, 2010.

REVISTA RELEGENS THRÉSKEIA - 2018 - UFPR - UEPA 
divulgadores das obras.

Tomemos por exemplo as imagens retratadas pelas primeiras expedições de pintores europeus, que desde o século XVI já vinham para o Brasil a mando da Coroa portuguesa, com a missão de registrar as paisagens, plantas, animais, assim como as "excentricidades" da vida dos indígenas brasileiros, as atitudes mais comuns do seu cotidiano, como a caça, a colheita, as festas, as brincadeiras, etc. Há de se levar em conta que o olhar desse artista já tinha um propósito, uma perspectiva calculada, ambos direcionados para justificar determinados fins ligados à política do colonizador e não do colonizado. Esse levantamento autoral- histórico será de grande valia para que o leitor tenha uma leitura crítica e problematizadora do que foi registrado, sem cair na ingênua compreensão de que essas ou quaisquer outras imagens retratam com fidelidade neutra a realidade. O levantamento da autoria e dos divulgadores das imagens é capaz de apontar os conflitos de diferentes naturezas, seja política, religiosa, econômica entre os diferentes grupos.

Como já dizia Rubem Alves "Ver é muito complicado" ( ALVES, 2004) , " ver" o universo religioso é ainda mais complexo, principalmente porque, como afirma Greschat,

os fiéis estão acostumados às figuras e às histórias que elas representam. Quem não pertence à mesma religião não sabe "ler" as formas e cores nem pode perguntar um "tradutor"; tem de adivinhar o que as representações significa, especificamente quando se trata de mensagens simbólicas (GRESCHAT, 2005,p.65)

Nesse sentido, cabe ao professor de Ensino Religioso, fundamentado na metodologia da Ciência da Religião, a tarefa nada fácil, de promover situações de ensino/ aprendizagem que proporcionem aos alunos de diferentes pertenças religiosas, ou mesmo sem nenhuma, fazer uma leitura das imagens que possa abarcar desde os aspectos editoriais, passando pelo conteúdo técnico (arte religiosa), até chegar ao conteúdo histórico e religioso, sem desprezar a experiência do leitor.

É preciso educar o olhar, ensinar a ver, mesmo sabendo como lembra Rubem Alves que existe algo que a ciência, a metodologia, não dão conta. Trata-se da subjetividade, dirão os cientistas, ou do espaço onde se desenvolve o Mistério, responderão os crentes.

A experiência é outro fator fundamental a ser considerado na leitura das 
imagens, como podemos ver no exemplo traduzido por Rubem Alves ao citar William Blake :

\begin{abstract}
A árvore que o sábio vê não é a mesma árvore que o tolo vê". Sei disso por experiência própria. Quando vejo os ipês floridos, sinto-me como Moisés diante da sarça ardente: ali está uma epifania do sagrado. Mas uma mulher que vivia perto da minha casa decretou a morte de um ipê que florescia à frente de sua casa porque ele sujava o chão, dava muito trabalho para a sua vassoura. Seus olhos não viam a beleza. Só viam o lixo. (BLAKE, in ALVES, 2004)
\end{abstract}

Conclusão

O objetivo deste artigo era enfatizar a relevância dos estudos sistemáticos das imagens para aprofundarmos o conteúdo religioso estudado, tendo os pressupostos teóricos e metodológicos da Ciência da Religião como referência.

Vimos que são muitos os suportes que nos deparamos para o estudo imagens, desde as divulgadas pelos meios de comunicação visual, até as retratadas em periódicos, museus etc. Porém, enquanto professores de Ensino Religioso, contamos que o livro didático é o que mais intermedia as relações de ensino/aprendizagem na sala de aula, das escolas particulares confessionais, o que implica em uma leitura crítica e reflexiva desse material.

A proposta aqui não era ser um manual de análise iconográfica, mas sim problematizar quais os critérios e princípios que podem nortear esta análise iconográfica.

Greschat é muito firme ao criticar o retardo dos cientistas da religião no estudo das imagens, que segundo ele por muito tempo ficou relegado a outros pesquisadores como "historiadores da arte e outros especialistas na área" (GRESCHAT, 2005, p. 67). Segundo o autor, no que se refere aos estudos dos textos religiosos o cientista da religião é vanguarda, mas no que se refere ao estudo das imagens somos "retaguarda " (GRESCHAT, 2005, p.74 ).

Com todo o exposto, a pretensão deste artigo seja colaborar para que os professores de Ensino Religioso, também saiam desta retaguarda com relação ao estudo das imagens e acreditem na importância desta proposta metodológica para a formação de cidadão mais críticos, mas reflexivos, pouco tolerantes aos estereótipos, as explicações maniqueísta da realidade, os preconceitos e as violências religiosas; porém 
extremamente comprometidos em promover uma sociedade que tenha por princípio o diálogo inter-religioso, o respeito `a pluralidade religiosa e a cultura da paz !

\section{Referências}

ALVES, Rubem. A complicada arte de ver. Folha de Sao Paulo online, 26 out. 2004. ALVES, Rubem. A complicada arte de ver. Folha de Sao Paulo online, 26 out. 2004. Sinapse

BITTENCOURT, Circe. Livro didático e saber escolar (1810-1910). Belo Horizonte: Autêntica, 2008.

CATECISMO DA IGREJA CATÓLICA. São Paulo: Loyola, 2005.

DINIZ, Débora; LIONÇO, Tatiana; CARRIÃO, Vanessa. Laicidade e Ensino Religioso no Brasil. Brasília: Letras Livres/Editora da UNB/Unesco, 2010.

GRESCHAT, Hans-Jürgen. $O$ que é ciência da Religião. trad. Frank Usarski. São Paulo: Paulinas, 2005.

JUNQUEIRA, Sérgio Rogério Azevedo KLUCK, Claudia Regina Condello Cândido de Oliveira. História do Livro Didático do Ensino Religioso brasileiro. In: X Congresso Brasileiro de História da Educação, v.10, n. 10, p. 1-10, 2014.

MANGUEL, Alberto. Lendo imagens: uma história de amor e ódio. São Paulo: Companhia das Letras, 2003.

PAIVA, Eduardo França. História e Imagens. Belo Horizonte: Autêntica, 2006.

PASSOS, João Décio. Ensino religioso: construção de uma proposta. Col. Temas do Ensino Religioso. São Paulo: Paulinas 2007.

PASTRO, Cláudio. Arte Sacra, o espaço sagrado hoje. Sao Paulo, Loyola, 1993.

PASTRO, Cláudio e TAVARES, André. Iconografia como expressão da fé In: MARIANI, Ceci Baptista \& VILHENA, Maria Angela (Orgs.). Teologia e arte: expressões de transcendência, caminhos de renovação . São Paulo: Paulinas ; 2011, p. $39-49$

SARTORELLI, Cesar Augusto. Artes Religisoas In. USARSKI; Frank e PASSOS, João Décio (org.). Compêndio de Ciência da Religião. São Paulo: Paulinas/Paulus, 2013. (p. 557-569)

SILVEIRA, Valeska Freman B. F. . Entre a teoria e a prática: limites da aplicação da Ciência da Religião na produçao dos livros didáticos de Ensino religioso no Fundamental I (Dissertação em Ciência da Religião ), PUC-SP, São Paulo, 2016.

SOARES, Afonso M.L. Religião e Educação. Da Ciência da Religião ao Ensino Religioso. Col. Temas do Ensino Religioso. São Paulo: Paulinas, 2010. 